\title{
Increase in incidence of disease due to diagnostic drift: primary liver cancer in Denmark, 1943-85
}

\author{
Inger Bak Andersen, Thorkild I A Sørensen, Anne Prener
}

\begin{abstract}
Objective-To examine the extent to which changes in diagnostic methods and classification are responsible for the striking increase in incidence of primary liver cancer in Denmark since 1943.

Design-Analysis of the time trends in sex specific, age standardised incidence of primary liver cancer and unspecified liver cancer (either secondary without known primary cancer or not specified as primary cancer) in the entire population from 1943 to 1985. By review of the 727 notifications from three periods of 5 years $(1948-52,1963-7$, and 1978-82) the changes in histological diagnosis and classification were assessed.
\end{abstract}

Setting-Denmark.

Subjects-Notifications of liver cancer to the Danish cancer registry.

Results-Concomitant with the increase in primary liver cancer, the incidence of the unspecified liver cancer declined. The proportion of histologically diagnosed primary liver cancer rose from $85 \%$ to $98 \%$, whereas the proportion for unspecified liver cancer rose from $12 \%$ to $51 \%$. When the proportion of primary versus unspecified liver cancer obtained by histological diagnosis was extrapolated to all cases, the annual incidence of primary liver cancer was 4.4 rather than 1.6 per 100000 population in 1948-52 and 6.0 rather than 5.5 per 100000 in 197882.

Conclusion-The increase in the incidence of primary liver cancer may be much smaller than the numbers of registered cases indicate. This example emphasises the need to consider diagnostic drift in time trend studies of disease incidence.

\section{Introduction}

Changes in incidence of diseases over time within populations may indicate changes in exposure of the population to one or more causes of the diseases. Therefore, time trend studies are important in the search for causes. Adequate long term planning of public health services may also require valid information on trends in disease incidence. The results of such studies depend, however, on changes in diagnostic processes, and these may produce apparent trends where no trends exist. Introduction of a new diagnostic method for screening may result in earlier and more frequent diagnosis of the disease than before and, in the clinical setting, in altered diagnostic classification.

Primary liver cancer is among the ten commonest cancers world wide and is particularly common in the developing countries. ${ }^{1}$ Recent studies have shown an appreciable increase in the incidence of primary liver cancer over the past decades. ${ }^{24}$ The increased incidence is seen both in high incidence areas such as south east Asia and southern Africa and in low incidence areas, such as Europe and the United States. The cause of this increase is not known, but it has been attributed to increased alcohol consumption, increased incidence of hepatitis $\mathrm{B}$ virus infection, and increased pollution. ${ }^{5}$ Assessment of the incidence of primary liver cancer is hampered by difficulties in obtaining definitive diagnosis and correct classification. As it is the incidence of registrations of primary liver cancer that has increased world wide it is possible that enhanced diagnostic precision has been a contributory factor.

We determined the time trends in Denmark from 1943 through 1985 of the sex specific, age standardised incidence of primary liver cancer and of unspecified liver cancer, and we examined the impact of changes during this period in histological diagnosis and classification.

\section{Methods}

Since 1943 the Danish cancer registry has received notifications of newly diagnosed cases of cancer from clinical and pathology departments of all Danish hospitals and practising physicians; its records have been supplemented with cases known only from death certificates. ${ }^{6}$ Diagnoses reported from 1943 to 1977 had been classified according to a modified version of the seventh revision of the International Classification of Diseases (ICD-7), ${ }^{7}$ which has been expanded to include certain information on histology and tumour behaviour. ${ }^{6}$ Since 1978 classification has been carried out according to both the International Classification of Diseases for Oncology (ICD- 0$)^{8}$ and the modified ICD7. This study includes all registrations since 1943 of primary liver cancer $(155 \cdot 0$ of ICD-7; "liver, malignant neoplasm, stated to be primary site") and unspecified liver cancer (156.0 of ICD-7; "malignant neoplasm of liver (secondary and unspecified)"). The sex specific, age standardised annual incidence rates (world standard $^{9}$ ) for primary liver cancer and unspecified liver cancer were calculated.

To determine the role of changes in classification and diagnostic precision we examined the original notifications, filed in the cancer registry, of 727 cases registered as 155.0 or 156.0 (ICD-7) during three five year periods: 1948-52, 1963-7, and 1978-82. For each period the appropriate sample size was calculated according to the total number of cases available and the estimated rate of diagnosis based on histological examination. The notifications were chosen at random from the total pool of cases within each five year period. By reviewing the original notifications we corrected the cases erroneously registered. The original notifications were not verified by reviewing clinical or pathology records or histology sections.

To evaluate the impact of changes over time in precise diagnostic classification we calculated for the three five year periods an age standardised annual incidence rate for primary liver cancer and unspecified liver cancer corrected for erroneous registration. 
Assuming that the ratio of primary liver cancer to unspecified liver cancer was the same for cases with and without histological diagnosis, we estimated an adjusted annual incidence rate for primary liver cancer and unspecified liver cancer.

The adjusted incidence of primary liver cancer was derived by first multiplying the incidence of liver cancer (primary or unspecified) without histological diagnosis by the ratio of the incidence of primary liver cancer to the incidence of all liver cancer among those with histological diagnosis and then adding the resulting incidence to the incidence of histologically diagnosed primary liver cancer. Subtracting the adjusted incidence of primary liver cancer from the incidence of all liver cancer gave the adjusted incidence of unspecified liver cancer.

The $95 \%$ confidence intervals for the proportion of erroneously registered diagnosis of primary and of unspecified liver cancer and for the proportion of histological diagnosis were estimated from the binomial distribution.

\section{Results}

TIME TRENDS OF INCIDENCE OF LIVER CANCER IN DENMARK I $943-85$

In both men and women the age standardised annual incidence rates of primary liver cancer have increased more than fivefold since 1943 (figure). The increase was especially pronounced from the late 1950 s to the mid-1960s; thereafter the increase continued but was less steep.

The age standardised annual incidence rates of unspecified liver cancer in both men and women showed a pronounced decrease from 1943 to the beginning of the 1960s (figure). After the mid-1960s the incidence was nearly constant.

TIME TRENDS IN HISTOLOGICAL DIAGNOSIS AND CLASSIFICATION I $948-82$

The review of the samples of original notifications to the cancer registry showed erroneous registrations in $1948-52$ of 23 out of 269 cases ( $9 \%$; $95 \%$ confidence interval: $6 \%$ to $13 \%$ ); in $1963-7$ of 33 out of 223 cases $(15 \% ; 11 \%$ to $20 \%)$; and in $1978-82$ of 22 out of 265

TABLE I-Diagnosis of tumours incorrectly registered as primary or unspecified liver cancer in samples from three five year periods in Denmark

\begin{tabular}{|c|c|c|c|c|c|c|c|}
\hline \multirow[b]{2}{*}{$\begin{array}{l}\text { Registered } \\
\text { diagnosis }\end{array}$} & \multirow[b]{2}{*}{$\begin{array}{l}\text { No of } \\
\text { registrations }\end{array}$} & \multirow[b]{2}{*}{ No checked } & \multirow{2}{*}{$\begin{array}{c}\text { No (\%) of } \\
\text { incorrect } \\
\text { diagnoses in } \\
\text { sample }\end{array}$} & \multicolumn{3}{|c|}{ No of corrected diagnoses } & \multirow{2}{*}{$\begin{array}{c}\text { No of } \\
\text { corrected } \\
\text { original } \\
\text { diagnoses }\end{array}$} \\
\hline & & & & $\begin{array}{l}\text { Primary liver } \\
\text { cancer }\end{array}$ & $\begin{array}{l}\text { Unspecified } \\
\text { liver cancer }\end{array}$ & $\begin{array}{l}\text { Extrahepatic } \\
\text { cancer }\end{array}$ & \\
\hline \multicolumn{8}{|c|}{ Primary liver cancer: } \\
\hline $1948-52$ & 215 & 117 & $17(15)$ & & 13 & 4 & 102 \\
\hline $1963-67$ & 636 & 126 & $20(16)$ & & 18 & 2 & 119 \\
\hline $1978-82$ & 1191 & 165 & $18(11)$ & & 15 & 3 & 147 \\
\hline \multicolumn{8}{|c|}{ Unspecified liver cancer: } \\
\hline $1948-52$ & 746 & 152 & $6(4)$ & 2 & & 4 & 159 \\
\hline $1963-67$ & 468 & 97 & $13(13)$ & 13 & & & 102 \\
\hline $1978-82$ & 623 & 100 & $4(4)$ & & & 4 & 111 \\
\hline
\end{tabular}

^Most cases were hepatic cancer not verified by histological examination.

TABLE II - Histological diagnosis of liver cancer in three five year periods in Denmark. Figures are numbers (percentages)

\begin{tabular}{|c|c|c|c|c|c|c|c|}
\hline & \multirow[b]{2}{*}{$\begin{array}{c}\text { No of } \\
\text { registrations }\end{array}$} & \multirow[b]{2}{*}{$\begin{array}{l}\text { No in } \\
\text { sample } f\end{array}$} & \multirow[b]{2}{*}{$\begin{array}{l}\text { Histological } \\
\text { verification }\end{array}$} & \multicolumn{4}{|c|}{ Method of verification ${ }^{\star}$} \\
\hline & & & & Necropsy & $\begin{array}{l}\text { Percutaneous } \\
\text { liver biopsy }\end{array}$ & Surgery & $\begin{array}{l}\text { Other } \\
\text { methods }\end{array}$ \\
\hline \multicolumn{8}{|c|}{ Primary liver cancer: } \\
\hline $1948-52$ & 215 & 102 & $87(85)$ & $80(78)$ & & $13(13)$ & $1(1)$ \\
\hline $1963-67$ & 636 & 119 & $114(96)$ & $104(87)$ & $10(8)$ & $28(24)$ & $2(2)$ \\
\hline $1978-82$ & 1191 & 147 & $144(98)$ & $114(76)$ & $23(16)$ & $31(21)$ & \\
\hline \multicolumn{8}{|c|}{ Unspecified liver cancer: } \\
\hline $1948-52$ & 746 & 159 & $19(12)$ & $11(7)$ & & $13(8)$ & $2(1)$ \\
\hline $1963-67$ & 468 & 102 & $40(39)$ & $16(16)$ & $8(8)$ & $31(30)$ & $1(1)$ \\
\hline $1978-82$ & 623 & 111 & $57(51)$ & $8(7)$ & $35(32)$ & $16(14)$ & $19(17)$ \\
\hline
\end{tabular}

${ }^{\star}$ In a few cases more than one method was used.

tWith correct diagnoses; see table I.

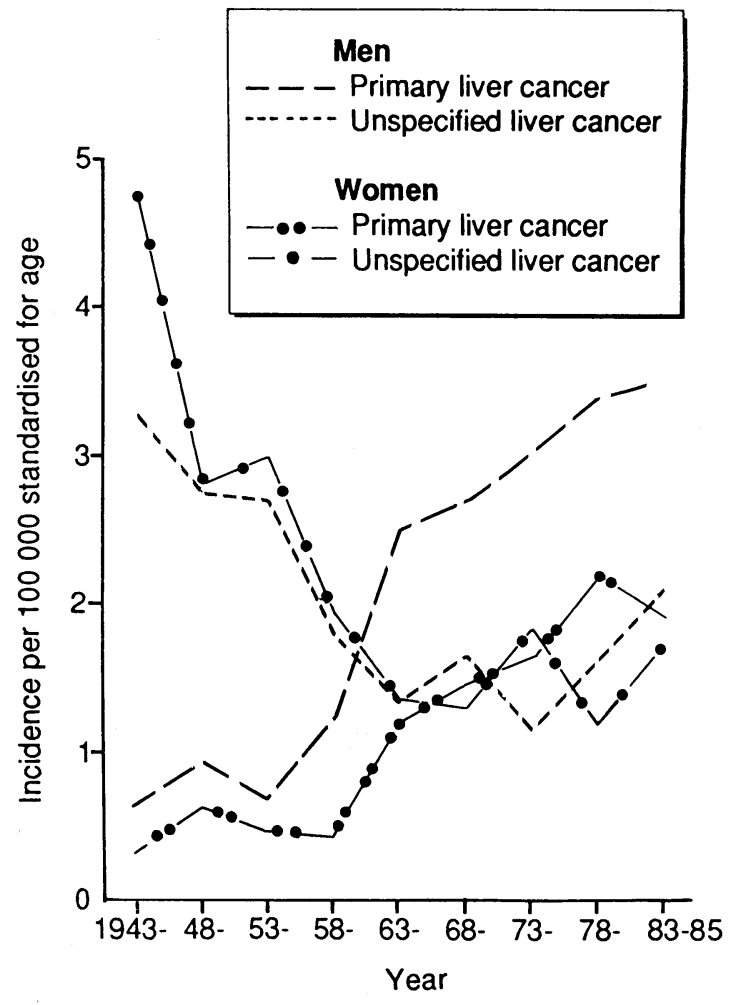

Trends in age standardised annual incidence rates of primary and unspecified liver cancer for men and women in Denmark, 1943-85

cases $(8 \% ; 5 \%$ to $12 \%)$. Table I shows the distributions of corrected cases of primary and unspecified liver cancer.

Histological diagnosis of primary liver cancer was frequent throughout the study period, but the slight increase from 87 out of 102 cases $(85 \% ; 76 \%$ to $91 \%)$ in the first period to 144 out of 147 cases $(98 \% ; 94 \%$ to $100 \%)$ in the third period was significant $\left(\chi^{2}=14.4\right.$; $\mathrm{p}<0.01$ ) (table II). The frequency of histological diagnosis of unspecified liver cancer increased significantly from 19 out of 160 cases $(12 \% ; 7 \%$ to $18 \%)$ in the first period to 57 out of 111 cases $(51 \% ; 41 \%$ to $60 \%)$ in the last period $\left(\chi^{2}=50.6 ; p<0.001\right)$.

Table II also shows the methods used for obtaining tissue for histological diagnosis as reported on the notifications. In most cases histological diagnosis was performed on only one occasion. For primary liver cancer necropsy was the most frequent method of diagnosis. Percutaneous liver biopsy had only a minor role in diagnosis of primary liver cancer, even in the last period, during which it was the main diagnostic tool for unspecified liver cancer.

Table III illustrates the changes in type of diagnosis of registered primary liver cancer in the three five year periods. Between 1948 and 1982 the type classification of primary liver cancer became more exact. In 1948-52 almost half of the cases of primary liver cancer were notified as "hepatic cancer" without further specification, even though the tumours were examined histologically, whereas in 1978-82 only 20 out of $147(14 \%)$ cases of primary liver cancer were notified in this way. In all three periods hepatocellular carcinoma constituted about half the cases of primary liver cancer. From 1948-52 to 1978-82 there was a slight, and nonsignificant, increase in the proportion of hepatocellular carcinoma. The type of primary liver cancer that increased most was intrahepatic cholangiocellular carcinoma.

TIME TRENDS IN ADJUSTED INCIDENCE OF PRIMARY LIVER CANCER AND UNSPECIFIED LIVER CANCER

In the study period the annual incidence rates adjusted for changes in diagnostic classification showed 


\begin{tabular}{|c|c|c|c|c|c|c|}
\hline & \multirow[b]{2}{*}{ No in sample } & \multicolumn{5}{|c|}{ Histological diagnosis } \\
\hline & & $\begin{array}{l}\text { Hepatocellular } \\
\text { carcinoma }\end{array}$ & $\begin{array}{l}\text { Cholangiocellular } \\
\text { carcinoma }\end{array}$ & $\begin{array}{l}\text { Mixed hepatocellular } \\
\text { and cholangiocellular } \\
\text { carcinoma }\end{array}$ & $\begin{array}{l}\text { Other primary liver } \\
\text { cancer }\end{array}$ & $\begin{array}{c}\text { Unspecified } \\
\text { histologically verified } \\
\text { primary liver cancer }\end{array}$ \\
\hline $1948-52$ & 102 & $50(49)$ & $6(6)$ & $1(1)$ & & $45(44)$ \\
\hline $1963-67$ & 119 & $67(56)$ & $18(15)$ & $5(4)$ & $2(2)$ & $27(23)$ \\
\hline $1978-82$ & 147 & $81(55)$ & $37(25)$ & $4(3)$ & $5(3)$ & $20(14)$ \\
\hline
\end{tabular}

*With correct diagnosis; see table I.

TABLE IV - Age standardised annual incidence rates per 100000 population for registrations of primary liver cancer and unspecified liver cancer in three five year periods in Denmark

\begin{tabular}{|c|c|c|c|c|c|}
\hline & Unadjusted & $\begin{array}{l}\text { Corrected for } \\
\text { erroneous } \\
\text { registration }\end{array}$ & $\begin{array}{l}\text { Histologically } \\
\text { verified }\end{array}$ & $\begin{array}{l}\text { Histologically } \\
\text { unverified }\end{array}$ & $\begin{array}{l}\text { Adjusted for changes } \\
\text { in diagnostic } \\
\text { classification }\end{array}$ \\
\hline \multicolumn{6}{|c|}{ Primary liver cancer: } \\
\hline $1948-52$ & 1.6 & $1 \cdot 4$ & $1 \cdot 2$ & $0 \cdot 2$ & $4 \cdot 4$ \\
\hline $1963-67$ & $3 \cdot 7$ & $3 \cdot 5$ & $3 \cdot 4$ & $0 \cdot 1$ & $4 \cdot 8$ \\
\hline 1978-82 & $5 \cdot 5$ & $4 \cdot 9$ & $4 \cdot 8$ & $0 \cdot 1$ & $6 \cdot 0$ \\
\hline \multicolumn{6}{|c|}{ Unspecified liver cancer: } \\
\hline $1948-52$ & $5 \cdot 4$ & $5 \cdot 6$ & $0 \cdot 7$ & 4.9 & $2 \cdot 6$ \\
\hline $1963-67$ & $2 \cdot 7$ & $2 \cdot 8$ & $1 \cdot 1$ & $1 \cdot 7$ & 1.5 \\
\hline $1978-82$ & $2 \cdot 8$ & $3 \cdot 1$ & 1.6 & 1.5 & $2 \cdot 0$ \\
\hline
\end{tabular}

$\star$ See table I.

†See table II.

a far smaller increase over time than the unadjusted incidence (table IV). Thus, the adjusted annual incidence of primary liver cancer increased $36 \%((6 \cdot 0$ $4 \cdot 4) / 4 \cdot 4$ ) from 1948 to 1982 and the unadjusted rate increased $224 \%((5 \cdot 5-1 \cdot 6) / 1 \cdot 6)$. The adjusted annual incidence for unspecified liver cancer decreased only slightly during this period.

\section{Discussion}

This study suggests that a main part of the dramatic increase in incidence of registered primary liver cancer may be ascribed to changes that have taken place in diagnostic procedures, which resulted in changes in the classification of liver cancer from unspecified to primary liver cancer. A similar time trend bias has been described for staging of lung cancer. ${ }^{10}$ The increased use of more sensitive techniques for staging resulted in classification of patients of the same kind from the clinical point of view into more advanced stages than before. This led to an apparent improvement over time in prognosis specific to stage.

In Denmark the incidence of registrations of primary liver cancer showed an increase of more than fivefold from 1943 to 1985 . In the same period the incidence of unspecified liver cancer showed a threefold decrease. In the period 1953-67 the increase in primary liver cancer and the decrease in unspecified liver cancer are especially apparent. At the beginning of the 1960s ultrasonic examination, Menghini's cannula for liver biopsy, and liver scintigraphy became common diagnostic tools in Denmark. Coincident with the use of these improved diagnostic tools, the use of histological diagnosis became more common for primary liver cancer and particularly for unspecified liver cancer. Therefore, it is likely that the dramatic increase in the incidence of primary liver cancer between 1953 and 1967 is a result of a more precise diagnostic classification of the group of liver cancers. On the other hand, the increase in incidence of primary liver cancer after 1967 cannot be explained by obvious improvements in diagnosis.

In all three periods the diagnosis of primary liver cancer was mainly based on necropsy, but the increasing incidence of primary liver cancer was not a result of a higher frequency of necropsies; the necropsy rate was constant at about $40 \%$ of all deaths in this period. ${ }^{11}$

To evaluate the impact of the changes in histological diagnosis we adjusted the incidence of primary liver cancer and unspecified liver cancer according to the results obtained in the group of cases with histological diagnosis. The adjusted incidence rates suggest that the increase in the incidence of primary liver cancer is rather modest. A real increase probably took place and was greatest during the late 1960 s and 1970 s, but it seems to be no more than a $40 \%$ increase. It seems reasonable to modify the conclusion drawn for time trend studies of liver cancer in other countries similarly. ${ }^{2-4}$

Accepting the modest increase in incidence of primary liver cancer, the question follows what the causes of this increase might be. The aetiology of primary liver cancer in Denmark is poorly investigated, but associations with use of alcohol, ${ }^{12}$ thorium dioxide, ${ }^{13}$ and aflatoxin $\mathrm{B}^{14}$ have been described. The exposure to aflatoxin in the Danish population has probably not had a great impact on the incidence of primary liver cancer. ${ }^{14}$ Between 1935 and 1946, 1026 Danish neurosurgical patients were injected with thorium dioxide, ${ }^{13}$ and at the latest follow up in 1978, 50 patients had developed primary liver cancer. Alcohol consumption in Denmark has increased noticeably in the past 30 years-from 4.3 litres pure alcohol per person aged over 14 in 1955 to 12.2 litres in $1984 .^{15}$ From 1961-74 mortality from alcoholic liver cirrhosis has increased fourfold in both men and women. ${ }^{16}$ Hepatocellular carcinoma is associated with alcohol consumption and liver cirrhosis, ${ }^{17}$ so it would be expected that the incidence of hepatocellular carcinoma would be increased correspondingly, but it showed only a modest increase between 1948 and 1982 . This suggests either that alcohol and liver cirrhosis are not the sole aetiological factors or, perhaps more likely, that there is a long time lag between changes in alcohol consumption, changes in incidence of cirrhosis, and changes in incidence of hepatocellular carcinoma.

The increase in the proportion of intrahepatic cholangiocellular carcinoma between 1948 and 1982 may not be real; it corresponds to a decrease in primary liver cancer histologically diagnosed but not classified by type, and the changes may reflect increasing awareness of this particular differential diagnosis of primary liver cancer among pathologists. On the other hand, we cannot exclude a real increase in this type of primary liver cancer. Resolution of this problem requires review of the histological specimens.

In conclusion, the incidence of primary liver cancer in Denmark increased from 1943 to 1985 , but the increase may be much smaller than indicated by the number of registrations of primary liver cancer. The increase in the incidence of registered primary liver cancer from 1953 to 1967 can almost entirely be explained by the increased use of more precise diagnostic procedures. This result exemplifies the importance of diagnostic drift in time trends in disease incidence.

We thank Bendix Carstensen for statistical help.

1 Anonymous. Report on a meeting of a WHO scientific group: prevention of primary liver cancer. Lancet 1983; i:463-5.

2 Saracci R, Repetto F. Time trends of primary liver cancer: indication of increased incidence in selected cancer registry populations. INCI 1980;65: $241-7$.

3 Hardell L, Bengtson NO, Jonsson U, Eriksson S, Lasson LG. Aetiological aspects on primary liver cancer with special regard to alcohol, organic aspects on primary liver cancer with special regard to alcohol, organic
solvents and acute intermittent porphyria - an epidemiological investigation. Brf Cancer 1984;50:389-97. 
4 Tuyns AJ, Obradovic M. Brief communication: unexpected high incidence of primary liver cancer in Geneva, Switzerland. $7 N C I$ 1975;54:61-4

Kew MC. Hepatocellular cancer: differences between high and low incidence regions. Lancet 1987;ii:1183-4.

6 Storm HH, Sprogel P, Bang S, Jensen OM. Cancer incidence in Denmark 1986 Copenhagen: Danish Cancer Society, 1989.

7 World Health Organisation. Manual of the international statistical classification of disesases, injuries and causes of death. Seventh revision, 1955. Geneva: World Health Organisation, 1957

8 World Health Organisation. International classification of diseases of oncology. First edition. Geneva: World Health Organisation, 1976.

9 Waterhouse J, Muir CS, Shanmugaratman K, Powell I. Cancer incidence in five continents: Vol IV. Lyon: International Agency for Research on Cancer, 1982. (Scientific publication No 42 .)

10 Feinstein AR, Sosin DM, Wells CK. The Will Rogers phenomenon: stage migration and new diagnostic techniques as a source of misleading statistics for survival in cancer. $N$ Engl f Med 1985;312:1604-8.
11 Storm $\mathrm{HH}$, Andersen J. Autopsy frequency in cancer patients in Denmark 1971-80. Ugeskr Laeger 1986;148:1110-4.

12 Jensen OM. Cancer morbidity and causes of death among Danish brewery workers. Lyon: International Agency for Research on Cancer, 1980.

13 Faber $M$. Twenty-eight years of continuous follow up of patients injected with thorotrast for cerebral angiography. Environ Res 1979;18:37-43.

14 Olsen JH, Dragsted L, Autrup H. Cancer risk and occupational exposure to aflatoxins in Denmark. Brf Cancer 1988;58:392-6.

15 Danmarks Statistik. Statistical yearbook 1986. Copenhagen: Danmarks Statistik, 1986:171.

16 Prytz H, Skinhøj P. Changing mortality from cirrhosis in Denmark 1965-78. Scand F Gastroenterol 1981;16:833-7.

17 Bassendine MF. Aetiological factors in hepatocellular cancer. In: Williams R, Johnson P, eds. Balliére's clinical gastroenterology. Vol 1. London: Tindall Bassendine, 1987:1-16.

(Accepted 4 December 1990)

\title{
Management of childhood diarrhoea by pharmacists and parents: Is Britain lagging behind the Third World?
}

\author{
Elizabeth Goodburn, Suely Mattosinho, Pyande Mongi, Tony Waterston
}

\section{Abstract}

Objective-To investigate the role of community pharmacists in providing advice and treatment for children with diarrhoea; to investigate mothers' responses to diarrhoea in their children.

Design-Cross sectional questionnaire study of a random selection of community pharmacists and of mothers attending child health clinics. Pharmacists were interviewed and given a questionnaire and a separate group was visited by a researcher posing as a parent; mothers were interviewed at the clinic.

Setting-Newcastle upon Tyne.

Subjects - 20 pharmacists were interviewed and visits by a researcher posing as a parent were carried out to 10 different pharmacists; 58 mothers were interviewed.

Main outcome measures-Advice given by pharmacists was contrasted with standard advice on management of diarrhoea in children.

Results-Half the pharmacists interviewed and $70 \%$ of pharmacists visited by a researcher posing as a parent recommended inappropriate treatment of childhood diarrhoea (such as antidiarrhoeal drugs and withholding breast milk), and only $30 \%$ at interview stated that they would ask for the age of the child. Mothers' knowledge of home treatment was inadequate. All pharmacists in the posed visits recommended a purchased treatment.

Conclusion-Pharmacists are widely used by parents for consultation for children's ailments but their advice is not always appropriate; hence they should be given more consistent training in recognising and managing clinical problems. Medical advice on management of diarrhoea is also inconsistent and should be modified to conform to the guidelines of the World Health Organisation.

\section{Introduction}

Since the late 1970s there has been considerable professional debate about the traditional role of the pharmacist in providing advice on symptoms and the significance of this role within primary health care. ${ }^{1-3}$ In 1983 a campaign called "Ask your Pharmacist" was launched by the National Pharmaceutical Association with the support of the Pharmaceutical Society of Great Britain. The general public is now being encouraged to consult the pharmacist about symptoms, and it is therefore essential that the advice given is safe, effective, and suited to the patient's particular condition.
Whereas in the 1960s much of the pharmacist's work was technical (compounding drugs, etc) the role of the pharmacist today often includes giving advice about general medical care, and many pharmacists believe that this aspect will gradually increase.

In the United Kingdom drugs are obtained primarily through prescription by hospital doctors and general practitioners and by over the counter sales at local pharmacies and supermarkets. There are three classes of products under the Medicines Act 1968 : (a) general sale list medicine (for example, oral rehydration salts, paracetamol) medicines that can be bought in supermarkets or over the counter in pharmacies at any time without a pharmacist on the premises; $(b)$ pharmacy medicine (for example, loperamide) medicines that can be obtained over the counter with no prescription, but a pharmacist must supervise the sale; $(c)$ prescription only medicine (for example, ampicillin).

Recognising the pharmacists' role in prescribing the Pharmaceutical Society has published advice on questions that should be asked when a patient presents at a pharmacy. ${ }^{6}$ A study on symptoms in adults, however, found the advice given by pharmacists to be less than adequate. ${ }^{4}$ In response there have been moves to provide more extensive training for pharmacy students on how to respond to symptoms, including those of children.

Little research has been done on advice given by pharmacists about complaints in children. A study carried out in Dundee in 1981 found that the pharmacists' advice varied considerably. ${ }^{7}$ Little attempt was made to elicit important symptoms, and the study concluded that the advice that pharmacists are giving regarding children is not generally appropriate, particularly for diarrhoea.

In 1981 Morrell found that diarrhoea was one of the six commonest symptoms in children under 16 years for which consultation was sought. ${ }^{2}$ Discussion with parents revealed the great anxiety that these symptoms may sometimes provoke and the enormous difficulty that some parents experience in deciding when to seek the general practitioner's care.

It has been our observation that the usual management of diarrhoea, both in hospitals and in the community in Britain, is different from that recommended by the World Health Organisation for developing countries. ${ }^{8}$ Our survey was designed to find out what mothers and pharmacists regard as important in treating diarrhoea in the United Kingdom; it focuses particularly on pharmacists' management of diarrhoea in children and also investigates mothers' management of diarrhoea at home. 